\title{
A Study on Synthesis and Characterization of Biobased Carbon Nanoparticles from Lignin
}

\author{
Prasad Gonugunta ${ }^{1,2}$, Singaravelu Vivekanandhan ${ }^{1,2}$, Amar K. Mohanty ${ }^{1,2}$, Manjusri Misra ${ }^{1,2^{*}}$ \\ ${ }^{1}$ School of Engineering, University of Guelph, Guelph, Canada \\ ${ }^{2}$ Bioproducts Discovery and Development Centre, Department of Plant Agriculture, \\ University of Guelph, Guelph, Canada \\ Email:*mmisra@uoguelph.ca
}

Received May 12, 2012; revised June 27, 2012; accepted July 2, 2012

\begin{abstract}
Carbon nanoparticles were synthesized using lignin as a renewable feedstock by employing a freeze-drying process followed by thermal stabilization and carbonization. The effect of adding various amounts of $\mathrm{KOH}$ to a lignin solution on the solubility of the lignin, the freeze-drying process, the thermal stabilization of the freeze-dried lignin, and carbon nanoparticle formation was investigated through FTIR, DSC, SEM, TEM and surface area analysis. SEM investigations confirmed that the freeze-drying process caused the formation of lignin with a porous microstructure. TEM analysis indicates that the thermal stabilization of freeze-dried lignin prevented the formation of agglomerated carbon nanoparticles during the carbonization process. The smallest carbon nanoparticles were found to be $25 \mathrm{~nm}$ and were prepared from the lignin precursor with $15 \% \mathrm{KOH}$.
\end{abstract}

Keywords: Carbon Nanoparticles; Lignin; Freeze-Drying; Carbonization

\section{Introduction}

Carbon nanostructures such as fullerenes, carbon nano tubes/fibres/particles, and graphene sheets have been extensively studied due to their unique properties such as good electrical/thermal conductivity, excellent corrosion resistance, and enhanced chemical/bio compatibility [15]. Hence, they have found a wide range of applications which include polymer composites, electrochemical energy storage and conversion, catalysis, filtration, hydrogen storage, and biotechnology [6-10]. Among the various carbon allotropes, particulate nanostructures receive more attention due to their versatility in fabrication and their extensive applications in polymer nanocomposites as nanofillers, waste-water treatment, biomedical imaging, and optical devices [11-14]. In general, these carbon nanoparticles have been synthesized using various synthetic processes including thermal carbonization, laser irradiation, sonication, and exfoliation [3,15-17].

One of the key factors in controlling the morphology and the yield of the carbon nanoparticles is the precursor material. Various carbon precursors such as graphite powders, petroleum pitch, carbon rich polymers, and other kinds of liquid/gaseous hydrocarbons have been extensively used for the fabrication of carbon nanoparticles $[5,16]$. However, there is a need for alternate carbon

\footnotetext{
"Corresponding author.
}

sources for the synthesis of carbonaceous materials due to increasing oil prices, depleting petroleum resources, their negative environmental impacts, and increasing demand for carbon-based nanomaterials in various emerging fields. Hence, renewable carbon resources such as plant biomasses, biobased oils, and hydrocarbons have been explored for the fabrication of carbon nanostructures $[18,19]$. Among the various renewable precursors, lignin, which is widely known as a co-product of pulp and second generation cellulosic ethanol industries, receives great attention due to its 1) carbon rich chemical structure, 2) abundance in nature, 3) chemical compatibility, and 4) cost effectiveness. Thus, lignin has been investigated for the fabrication of carbonaceous materials such as carbon fibres and activated carbons. However, the synthesis of carbon nanoparticles from lignin has not been explored to a great extent $[20,21]$. Synthesis of carbon nanoparticles with controlled microstructures is possible through chemical modification and alteration of the processing parameters. In this, the challenging issue is to inhibit the agglomeration of lignin molecules during the carbonizetion process.

Herein, we report the synthesis of carbon nanoparticles using lignin as a renewable feedstock by adopting a freeze-drying process in order to overcome the issues related to the formation of lumps during carbonization. Our ultimate aim is to investigate the effect of $\mathrm{KOH}$ ad- 
dition on the solubility of lignin, the freeze-drying process, and thermal stabilization as well as the formation of carbon nanoparticles. Freeze-drying of solubilized lignin can effectively produce ultra porous lignin structures. The thermal stabilization is involved in the retention of the obtained microstructure during the carbonizing process. This will help to avoid the agglomeration of carbon particles as well as the formation of lumps during the carbonization process and result in ultrafine nanoparticles. The complete process was investigated using FTIR, DSC, SEM, and TEM.

\section{Experimental}

\subsection{Materials}

Protobind 2400 lignin (PL) is a by-product of the paper industries and was obtained from A L M Pvt. Ltd. India. Potassium hydroxide (KOH) in pellet form was procured from Sigma Aldrich and both the precursors were used as-received without further purification.

\subsection{Methods}

Figure 1 shows a schematic representation of the various steps involved in the synthesis of carbon nanoparticles from lignin. Step 1: $2 \mathrm{~g}$ of lignin samples were dissolved in $500 \mathrm{ml}$ of deionised water with various $\mathrm{KOH}$ concentrations such as $0 \mathrm{wt} \%, 5 \mathrm{wt} \%, 10 \mathrm{wt} \%$, and $15 \mathrm{wt} \%$ under sonication. The obtained solutions were labeled as PL-0, PL-5, PL-10, and PL-15 respectively. Step 2: Brown coloured lignin solutions were transferred into steel beakers and solidified using liquid nitrogen. The solidified lignin samples were freeze-dried in order to achieve porous lignin. Step 3: Thermal stabilization of the freeze-dried lignins was performed by heating them up to $250^{\circ} \mathrm{C}$ at a $1^{\circ} \mathrm{C} / \mathrm{min}$ ramp rate. This helps in retention of the porous microstructure during the carbonizetion process. Step 4: After the thermal stabilization, process, thermo stabilized lignin samples were carbonized in a tubular furnace at $700^{\circ} \mathrm{C}$ for 2 hours under nitrogen atmosphere by employing a $5^{\circ} \mathrm{C} / \mathrm{min}$ heating rate. The obtained carbon nanoparticles were used for further characterization.

\subsection{Characterization Techniques}

A SAVANT-MODULYO (Model No: B1576) freeze dryer was used to dry lignin solutions, which allows the formation of porous lignin. The effect of thermal stabilization on the structural coordination of freeze-dried lignin was investigated using Fourier transform infrared spectroscopy (FTIR), Thermo Scientific Nicolet TM 6700 FT-IR Spectrometer, USA employing attenuated total reflection infrared (ATR-IR) mode between 400 $\mathrm{cm}^{-1}$ and $4000 \mathrm{~cm}^{-1}$ with a resolution of $4 \mathrm{~cm}^{-1}$. Differential Scanning Calorimetric (DSC) analysis of the as-obtained as well as the thermo-stabilized freeze-dried lignin was performed using a TA Q-200 DSC in order to identify the glass transition temperatures $\left(\mathrm{T}_{\mathrm{g}}\right) .3$ to $5 \mathrm{mg}$ of lignin samples were sealed in an aluminum pan supplied by TA instruments. Initially, the sample was heated to and maintained at $80^{\circ} \mathrm{C}$ for 30 minutes in order to remove existing moisture and then cooled to $0^{\circ} \mathrm{C}$. The DSC thermogram was recorded up to $250^{\circ} \mathrm{C}$ employing a $20^{\circ} \mathrm{C}$ $/$ min ramp rate. All analysis was carried out in a nitrogen atmosphere.The micro-structure of the lignin samples were analyzed using a scanning electron micro-scope (SEM), FEI Inspect S50 Netherlands. Gold coating was
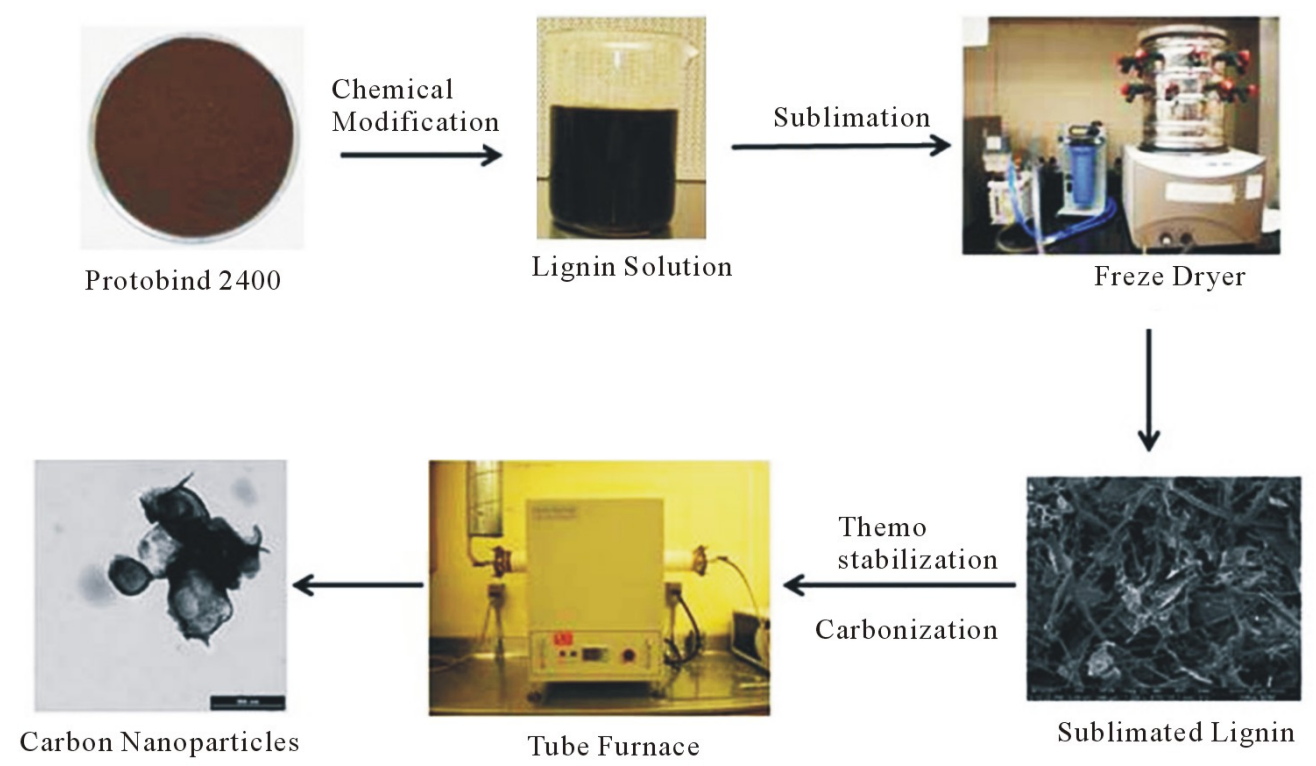

Figure 1. Schematic of the various steps involved in the synthesis of carbon nanoparticles from lignin. 
performed for all the samples in order to enhance the SEM images. Synthesized carbon nanoparticles were characterized using a transmission electron microscope (TEM), JEOL 2010F FEG TEM/STEM, employing a 200 $\mathrm{kV}$ operating voltage. Brunauer-Emmet-Teller (BET) surface area analysis of the freeze-dried lignin samples and the synthesized carbon nanoparticles were measured with a NOVA station-C, Quantachrome through nitrogen gas sorption at $77.3 \mathrm{~K}$. First, the samples were flow degased at $55^{\circ} \mathrm{C}$ for $8-16$ hours to remove the volatiles. BET surface areas were taken from a multipoint plot over a P/Po range of $0.05-0.35$.

\section{Results and Discussion}

The freeze-drying process caused the formation of porous lignin samples. However, these may fuse together and form lumps during the carbonization process, which results in bulk carbon material rather than well-defined carbon nanoparticles. In order to retain this porous structure, lignin samples underwent a thermal stabilization process employing a low heating rate of $1^{\circ} \mathrm{C} / \mathrm{min}$ at $250^{\circ} \mathrm{C}$ for 2 hours. The effect of thermal stabilization on their structural coordination, thermal behavior, and microstructure were investigated by FTIR, DSC, and SEM analysis respectively. Figure 2 shows the FTIR spectra of the as-obtained and thermo stabilized lignin with different $\mathrm{KOH}$ formulations. From Figure 2, the FTIR spectra indicates a characteristic peak of the lignin at $1590 \mathrm{~cm}^{-1}$ and $1500 \mathrm{~cm}^{-1}$, which represents the aromatic skeletal vibration [22]. Thermal stabilization of the freeze-dried lignin caused shifting of the peak at 1590 $\mathrm{cm}^{-1}$, which also increases with increasing $\mathrm{KOH}$ concentration for both the freeze-dried as well as thermo stabilized lignins. During the thermal stabilization, lignin undergoes condensation reactions in the presence of alkali metals, which also caused the formation of various organic compounds such as metal formates as well as acetates [22]. These metal carboxylates have a very strong absorbance in the region of $1695-1540 \mathrm{~cm}^{-1}$, which caused the increased peak intensity at $1590 \mathrm{~cm}^{-1}$ [23]. Thermal stabilization also caused the formation of new peaks at $1385 \mathrm{~cm}^{-1}$ and $1315 \mathrm{~cm}^{-1}$, which is attributed to C-O-C stretching, which evidences the formation of excess ether groups through condensation. This results in higher cross-linking and caused significant improvement in the glass transition temperature.

Figure 3 exhibits the DSC thermograms of freezedried lignin before and after thermo stabilization. The DSC thermogram of freeze-dried lignin derived without $\mathrm{KOH}$ addition shows a $\mathrm{T}_{\mathrm{g}}$ of $89^{\circ} \mathrm{C}$, which increases with increasing $\mathrm{KOH}$ concentration. Ucar et al. reported that the presence of alkali metal in lignin effectively caused the cross-linking through condensation, which also results
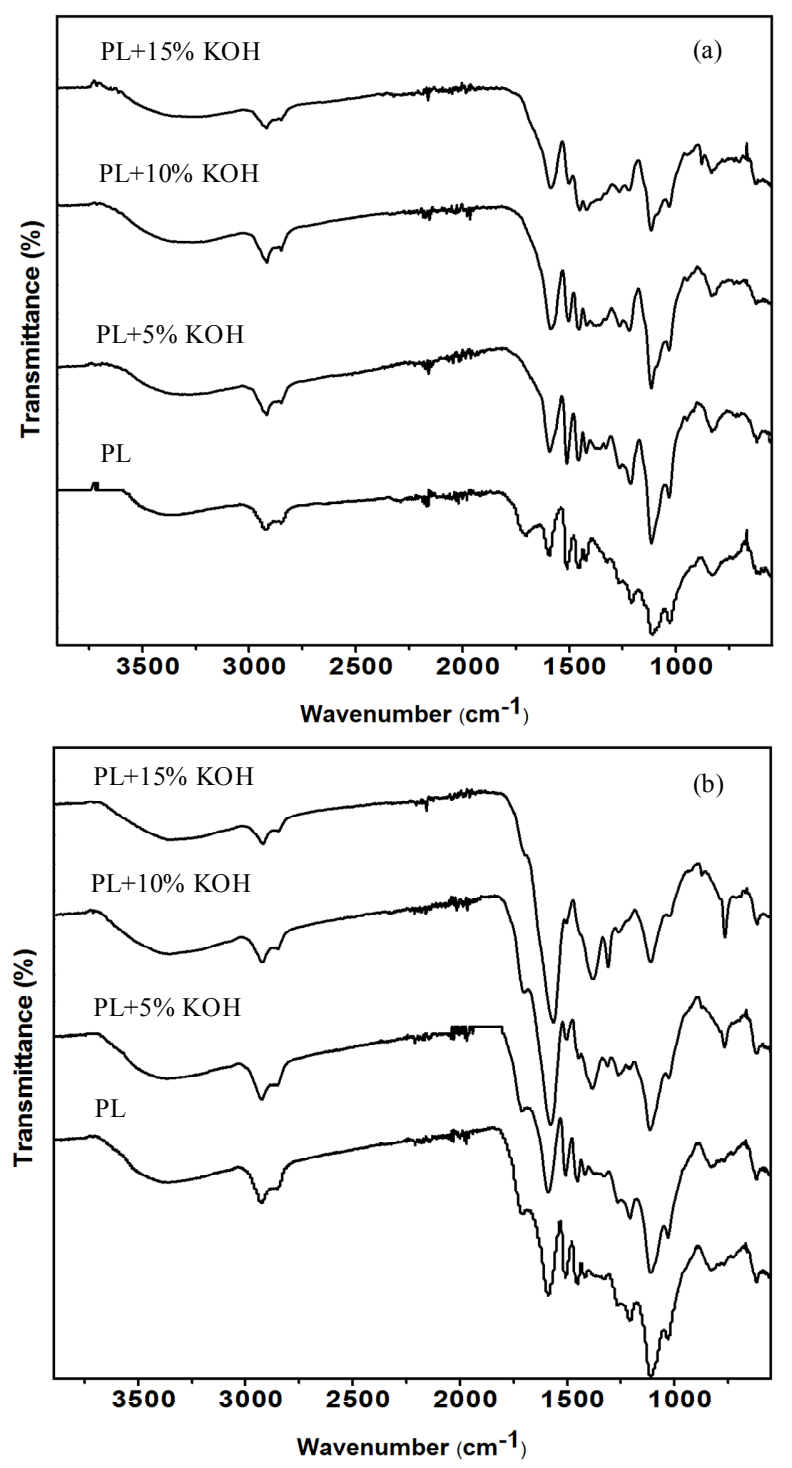

Figure 2. FTIR spectra of freeze-dried lignin (a) as derived and (b) thermal stabilized.

in the increased $\mathrm{T}_{\mathrm{g}}$ in the DSC thermogram.

Thermo stabilization further enhances the condensation/cross-linking significantly thereby increasing the glass transition temperature and retaining the glassy state of lignin, which is confirmed through the DSC thermograms which do not show a significant $\mathrm{T}_{\mathrm{g}}$ point. During thermal stabilization, lower heating rates increase the $T_{g}$ of the lignin samples faster than the actual temperature, thereby avoiding the possibility of fusing and stabilizing the foamy structure. SEM analysis confirms this phenomenon, which is shown in Figure 4. The freeze-drying process caused the formation of porous structures, which is highly influenced by the presence of $\mathrm{KOH}$. The freeze-dried lignin solution made without $\mathrm{KOH}$ addition formed a caused the formation of solid mass. Further, the thermal stabilization caused the successful retention of 

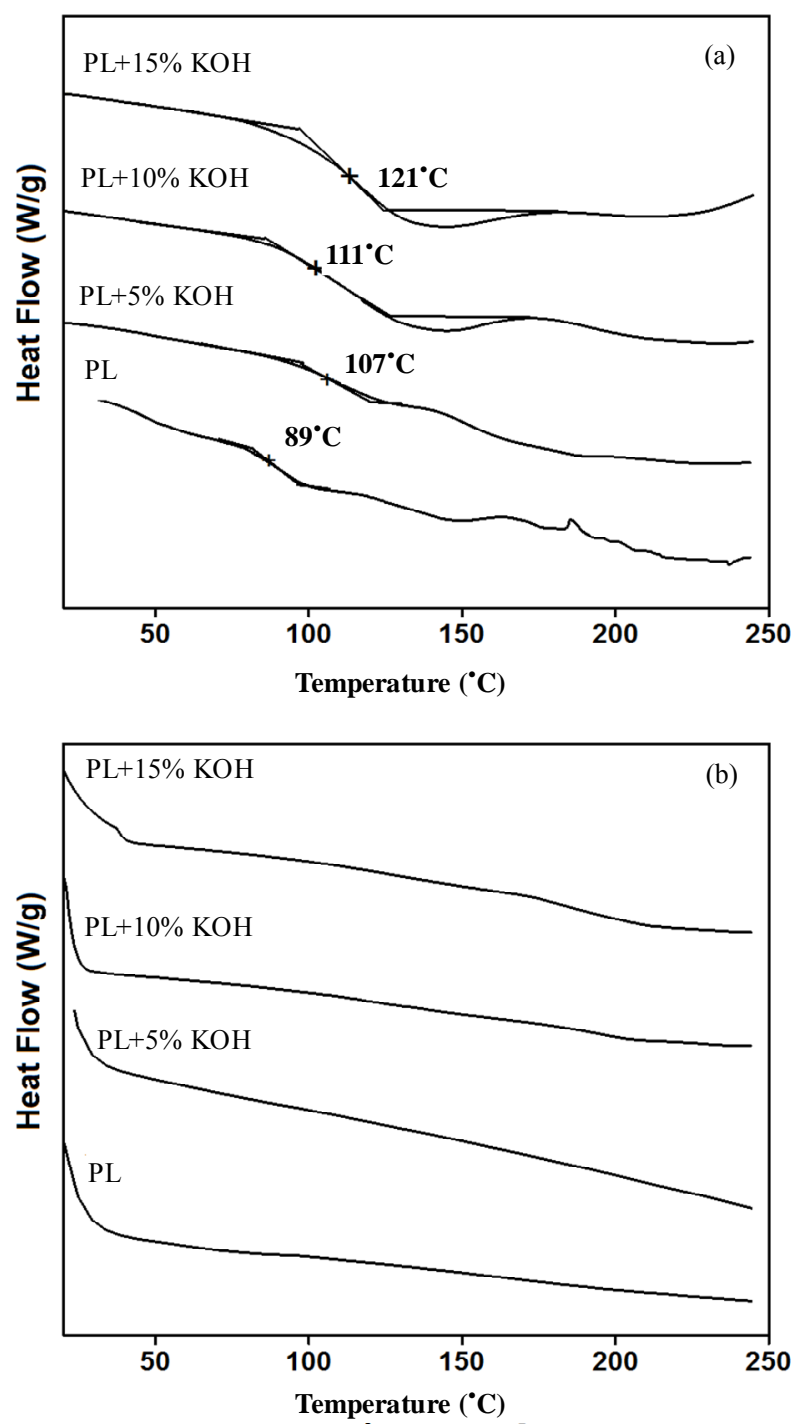

Figure 3. DSC thermogram of freeze-dried lignin (a) as derived and (b) thermo stabilized.

porous structure. This result is consistent with the reported literature by Kadla et al. [20].

Thermol stabilized lignin samples were carbonized at $700^{\circ} \mathrm{C}$ in nitrogen atmosphere for 2 hours. It was observed that the carbonized lignin without $\mathrm{KOH}$ results in the formation of solid mass where as the lignin samples modified with $\mathrm{KOH}$ yielded ultrafine particles. The challenging issue in fabricating carbon nanoparticles is the yield, which indicates the efficiency of the conversion process. The thermal stabilization yield fraction $\left(Y_{T S}\right)$ is the ratio of mass of lignin present after thermal stabilization $\left(m_{T S}\right)$ to before $\left(m_{T S}\right)$ thermo stabilization process. Similarly, carbonization yield fraction $\left(Y_{C}\right)$ is the ratio of mass of carbonized material $\left(m_{C}\right)$ to mass of material present before carbonization process $\left(m_{T S}\right)$. Overall yield is the product of the yields of thermal stabilization $\left(Y_{T S}\right)$ and the carbonization $\left(Y_{C}\right)$.
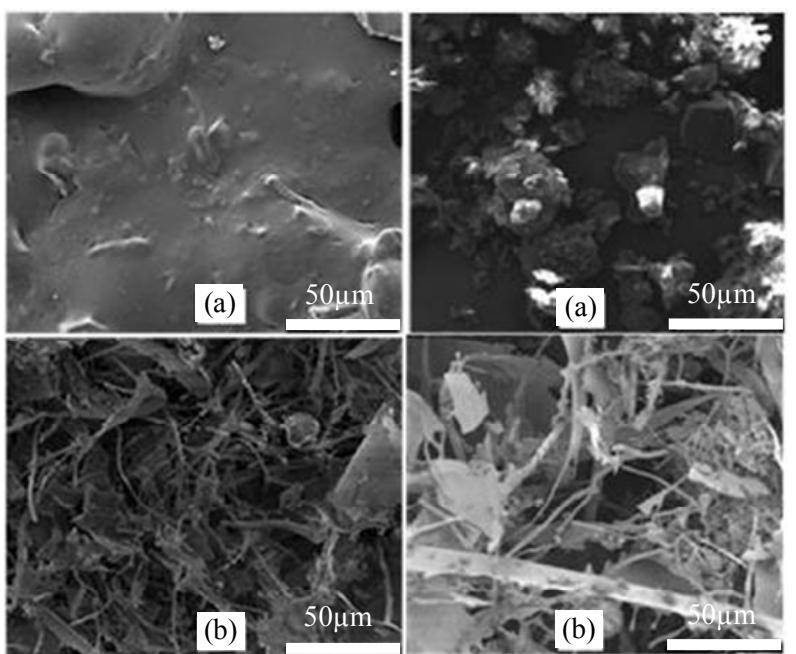

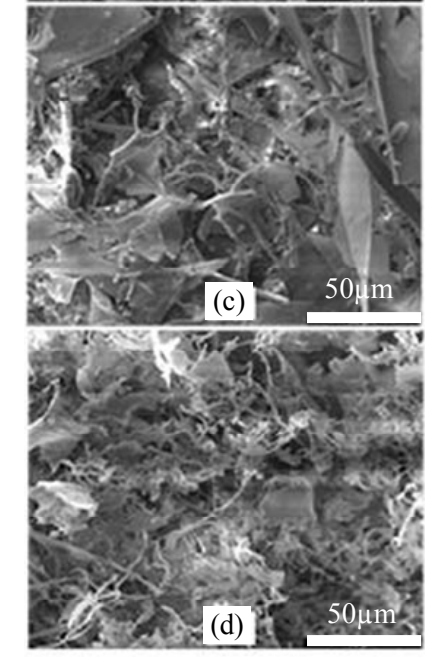

(I) As derived

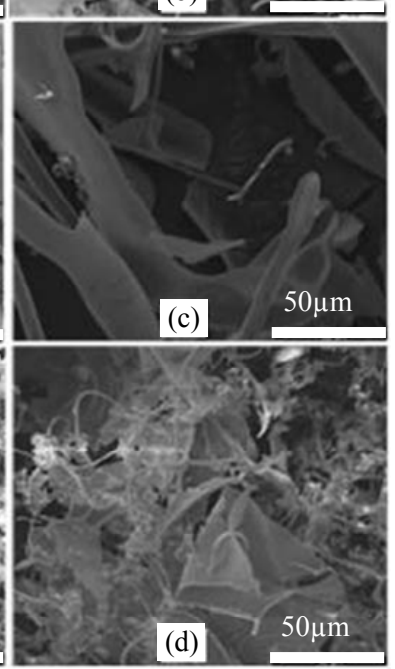

(II) Thermo-stabilized
Figure 4. SEM micrographs of freeze-dried lignin (I) as derived and (II) thermo stabilized ((a) PL; (b) PL + 5 wt \% KOH; (c) PL + 10 wt \% KOH; (d) PL + 15 wt \% KOH).

$$
\begin{gathered}
Y_{T S}=\frac{m_{T S}}{m_{T S}^{0}} \\
Y_{C}=\frac{m_{C}}{m_{T S}} \\
Y_{T}=\left(Y_{T S}\right) *\left(Y_{C}\right)=\left(\frac{m_{T S}}{m_{T S}^{0}}\right) *\left(\frac{m_{C}}{m_{T S}}\right)=\left(\frac{m_{C}}{m_{T S}^{0}}\right)
\end{gathered}
$$

Table 1 summarizes the yields during the various stages involved in the synthesis of carbon nanoparticles.

The specific surface area of the synthesized carbon nanoparticles were measured by employing BET surface area analysis The measured surface area of the carbon nanoparticles synthesized from lignin with different $\mathrm{KOH}$ concentrations of $0 \%, 5 \%, 10 \%$, and $15 \%$ are 0,43 , 47 , and $23 \mathrm{~m}^{2} / \mathrm{g}$ respectively. From this analysis, it is confirmed that the addition of $\mathrm{KOH}$ to lignin up to $10 \%$ 
increases the surface area and higher concentrations of $\mathrm{KOH}$ decreases the surface area. This may be due to the tendency of $\mathrm{KOH}$ to form agglomerates at higher $\mathrm{KOH}$ concentrations $(15 \%)$.

The results indicate that the addition of $\mathrm{KOH}$ reduces the overall yield, which may be due to the oxidation behavior of $\mathrm{KOH}$ in lignin. Synthesized carbon powders were further characterized by TEM analysis to confirm the formation of nanoparticles. TEM micrographs of the carbon particles prepared from lignin source modified with different $\mathrm{KOH}$ concentration are shown in Figure 5.

\section{Conclusion}

Carbon nanoparticles were successfully synthesized using lignin (Protobind 2400), a industrial co-product, as a renewable feedstock. The effect of $\mathrm{KOH}$ addition on the solubility of lignin, the freeze-drying process, thermal

Table 1. Yields for thermally stabilized and carbonized carbon nanoparticles.

\begin{tabular}{cccc}
\hline $\begin{array}{c}\text { Sample } \\
\text { name }\end{array}$ & $\begin{array}{c}\text { Yield of thermal } \\
\text { stabilization } \\
\left(Y_{T S} \%\right)\end{array}$ & $\begin{array}{c}\text { Yield of } \\
\text { carbonization } \\
\left(Y_{C} \%\right)\end{array}$ & $\begin{array}{c}\text { Overall yield } \\
\left(Y_{T} \%\right)\end{array}$ \\
\hline PL & $92.88 \pm 1.3$ & $52.847 \pm 1.11$ & 49.08 \\
$\begin{array}{c}\mathrm{PL}+5 \\
\mathrm{wt} \% \mathrm{KOH}\end{array}$ & $88.46 \pm 2.5$ & $55.072 \pm 1.9$ & 48.71 \\
$\begin{array}{c}\mathrm{PL}+10 \\
\mathrm{wt} \% \mathrm{KOH}\end{array}$ & $75.97 \pm 3.1$ & $56.7 \pm 2.1$ & 43.07 \\
$\begin{array}{c}\mathrm{PL}+15 \\
\mathrm{wt} \% \mathrm{KOH}\end{array}$ & $66.82 \pm 3.5$ & $57.8 \pm 2.5$ & 38.61 \\
\hline
\end{tabular}

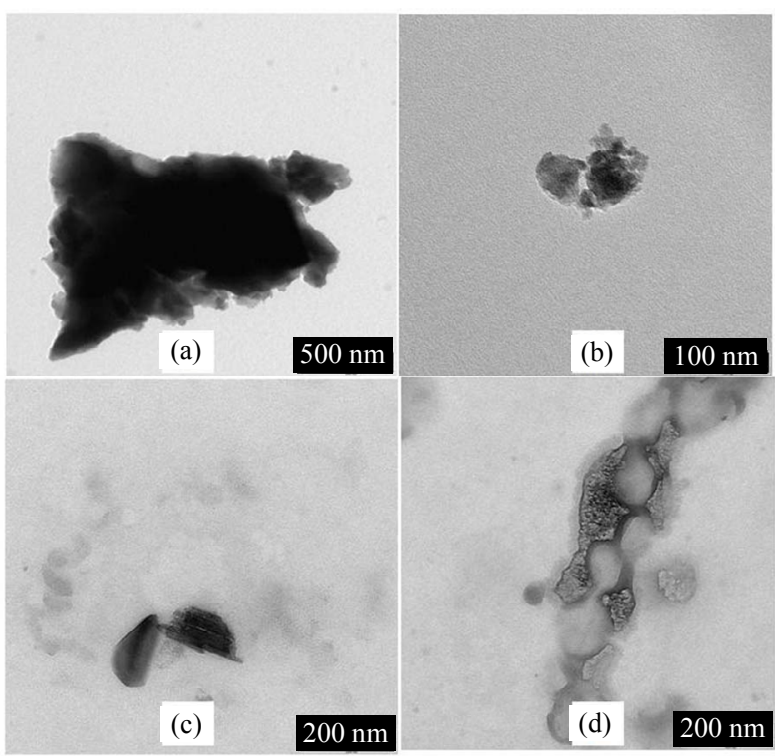

Figure 5. TEM image of carbon nanoparticles synthesized from (a) Protobind 2400; (b) Protobind $2400+5$ wt\% KOH; (c) Protobind $2400+10$ wt \% KOH; and (d) Protobind 2400 +15 wt \% KOH. stabilization, and the carbonization behavior was investigated. Freeze-drying inhibited agglomeration during the thermal stabilization process and resulted in the formation of lignin with foamy and porous structures. Thermal stabilization of the freeze-dried lignin caused condensation followed by cross linking reactions which increased the $T_{g}$ of the lignin gradually; thereby retaining its glassy nature beyond its degradation temperature as confirmed by FTIR and DSC analysis. The carbonization of the thermal stabilized lignin caused the formation of carbon nanoparticles with a size range between 25 and $150 \mathrm{~nm}$. TEM analysis of these synthesized carbon nanoparticles indicates that the addition of $\mathrm{KOH}$ influences their particle size significantly.

\section{Acknowledgements}

The authors are thankful to the Ontario ministry of agriculture, food and rural affairs (OMAFRA) new directions and alternative renewable fuels research program (2009) for supporting this research.

\section{REFERENCES}

[1] O. Shenderova, V. Zhirnov and D. Brenner, "Carbon Nanostructures," Critical Reviews in Solid State and Material Sciences, Vol. 27, No. 3-4, 2002, pp. 227-356. doi:10.1080/10408430208500497

[2] S. Iijima and T. Ichihashi, "Single-Shell Carbon Nanotubes of 1-nm Diameter," Nature, Vol. 363, No. 6430, 1993, pp. 603-605.

[3] J. Lu, J. Yang, J. Wang, A. Lim, S. Wang and K. P. Loh, "One-Pot Synthesis of Fluorescent Carbon Nanoribbons, Nanoparticles, and Graphene by the Exfoliation of Graphite in Ionic Liquids," ACS Nano, Vol. 3, No. 8, 2009, pp. 2367-2375. doi:10.1021/nn900546b

[4] A. K. Geim and K. S. Novoselov, "The Rise of Graphene," Nature Materials, Vol. 6, No. 3, 2007, pp. 183-191. doi:10.1038/nmat1849

[5] Y. Wang, S. Serrano and J. Santiago-Aviles, "Conductivity Measurement of Electrospun PAN-Based Carbon Nanofiber," Journal of Materials Science Letters, Vol. 21, No. 13, 2002, pp. 1055-1057. doi:10.1023/A:1016081212346

[6] P. Ajayan and O. Zhou, "Applications of Carbon Nanotubes," Carbon Nanotubes, Vol. 80, 2001, pp. 391-425. doi:10.1007/3-540-39947-X_14

[7] R. H. Baughman, A. A. Zakhidov and W. A. De Heer, "Carbon Nanotubes-The Route toward Applications," Science, Vol. 297, No. 5582, 2002, pp. 787-792. doi:10.1126/science.1060928

[8] W. Choi, I. Lahiri, R. Seelaboyina and Y. S. Kang, "Synthesis of Graphene and Its Applications: A Review," Critical Reviews in Solid State and Materials Sciences, Vol. 35, No. 1, 2010, pp. 52-71. doi:10.1080/10408430903505036

[9] N. Sinha and J. T. W. Yeow, "Carbon Nanotubes for 
Biomedical Applications," IEEE Transactions on NanoBioscience, Vol. 4, No. 2, 2005, pp. 180-195. doi:10.1109/TNB.2005.850478

[10] E. Frackowiak and F. Beguin, "Electrochemical Storage of Energy in Carbon Nanotubes and Nanostructured Carbons," Carbon, Vol. 40, No. 10, 2002, pp. 1775-1787. doi:10.1016/S0008-6223(02)00045-3

[11] S. C. Ray, A. Saha, N. R. Jana and R. Sarkar, "Fluorescent Carbon Nanoparticles: Synthesis, Characterization, and Bioimaging Application," Journal of Physical Chemistry C, Vol. 113, No. 47, 2009, pp. 18546-18551. doi:10.1021/jp905912n

[12] J. Yu, Q. Zhang, J. Ahn, S. F. Yoon, Rusli, Y. J. Li, B. Gan and K. Chew, "Synthesis of Carbon Nanoparticles by Microwave Plasma Chemical Vapor Deposition and Their Field Emission Properties," Journal of Materials Science Letters, Vol. 21, No. 7, 2002, pp. 543-545. doi:10.1023/A:1015456921100

[13] R. Haydarov and O. Gapurova, "Application of Carbon Nanoparticles for Water Treatment, Water Treatment Technologies for the Removal of High-Toxicity Pollutants," In: M. Václavíková, K. Vitale, G. P. Gallios and L. Ivaničová, Eds., Water Treatment Technologies for the Removal of High-Toxicity Pollutants, Springer, Berlin, 2010, pp. 253-258. doi:10.1007/978-90-481-3497-7_25

[14] M. M. Saatchi and A. Shojaei, "Mechanical Performance of Styrene-Butadiene-Rubberfilled with Carbon Nano Particles Prepared by Mechanical Mixing," Materials Science and Engineering: A, Vol. 528, No. 24, 2011, pp. 7161-7172. doi:10.1016/j.msea.2011.05.089

[15] T. Akiyama, N. Akae, M. Hayasaka and N. Ishikawa, "Nanoparticle Recovery Using a Fume Collector Comprised of Carbonized Refuse-Derived Fuel," Metallurgical and Materials Transactions B, Vol. 35, No., 2004, pp. 993-998.

[16] S. L. Hu, K. Y. Niu, J. Sun, J. Yang, N. Q. Zhao and X.
W. Du, "One-Step Synthesis of Fluorescent Carbon Nanoparticles by Laser Irradiation," Journal of Materials Chemistry, Vol. 19, No. 4, 2009, pp. 484-488. doi:10.1039/b812943f

[17] H. Li, X. He, Y. Liu, H. Huang, S. Lian, S. T. Lee, et al., "One-Step Ultrasonic Synthesis of Water-Soluble Carbon Nanoparticles with Excellent Photoluminescent Properties," Carbon, Vol. 49, No. 2, 2011, pp. 605-609. doi:10.1016/j.carbon.2010.10.004

[18] M. Sharon, "Carbon Nanomaterials and Their Synthesis from Plant-Derived Precursors," Synthesis and Reactivity in Inorganic, Metal-Organic and Nano-Metal Chemistry, Vol. 36, No. 3, 2006, pp. 265-279. doi:10.1080/15533170600596048

[19] K. Sudo and K. Shimizu, "A New Carbon Fiber from Lignin," Journal of Applied Polymer Science, Vol. 44, No. 1, 1992, pp. 127-134. doi:10.1002/app.1992.070440113

[20] P. Carrott and M. Ribeiro Carrott, "Lignin-From Natural Adsorbent to Activated Carbon: A Review," Bioresource Technology, Vol. 98, No. 12, 2007, pp. 2301-2312. doi:10.1016/j.biortech.2006.08.008

[21] J. Kadla, S. Kubo, R. Venditti, R. Gilbert, A. Compere and W. Griffith, "Lignin-Based Carbon Fibers for Composite Fiber Applications," Carbon, Vol. 40, No. 15, 2002, pp. 2913-2920. doi:10.1016/S0008-6223(02)00248-8

[22] G. Ucar, D. Meier, O. Faix and G. Wegener, "Analytical Pyrolysis and FTIR Spectroscopy of Fossil Sequoiadendron Giganteum (Lindl.) Wood and MWLs Isolated Hereof," European Journal of Wood and Wood Products, Vol. 63, No. 1, 2005, pp. 57-63. doi:10.1007/s00107-004-0530-x

[23] G. Socrates, "Infrared and Raman Characteristic Group Frequencies: Tables and Charts," John Wiley \& Sons Inc., New York, 2004. 